\title{
Application of a Small Molecule Radiopharmaceutical Concept to Improve Kinetics
}

\author{
Jae Min Jeong ${ }^{1,2}$
}

Received: 8 July 2015 / Revised: 3 September 2015 / Accepted: 7 September 2015 / Published online: 28 September 2015

(C) Korean Society of Nuclear Medicine 2015

\begin{abstract}
Recently, large molecules or nanoparticles are actively studied as radiopharmaceuticals. However, their kinetics is problematic because of a slow penetration through the capillaries and slow distribution to the target. To improve the kinetics, a two-step targeting method can be applied by using small molecules and very rapid copper-free click reaction. Although this method might have limitations such as internalization of the first targeted conjugate, it will provide high target-to-nontarget ratio imaging of radiopharmaceuticals.
\end{abstract}

The majority of radiopharmaceuticals belong to small molecules of which the molecular weight is less than $2000 \mathrm{Da}$, and the molecular size is smaller than $2 \mathrm{~nm}$ generally. The outstanding feature of the small molecule radiopharmaceuticals compared to large molecules is with their kinetics. Their distribution to target and clearance from non-target tissues are very rapid, which is the essential requirement of radiopharmaceuticals.

The penetration of these small radiopharmaceuticals through the cell membrane mainly depends on the lipophilicity. Lipophilic radiopharmaceuticals can penetrate cell membranes rapidly and show rapid tissue distribution. For example, $\left[{ }^{123} \mathrm{I}\right] \mathrm{IMP},{ }^{99 \mathrm{~m}} \mathrm{Tc}-\mathrm{HMPAO}$, and ${ }^{99 \mathrm{~m}} \mathrm{Tc}-\mathrm{ECD}$ are very

Jae Min Jeong

jmjng@snu.ac.kr

1 Department of Nuclear Medicine, Seoul National University College of Medicine, Seoul, Korea

2 Department of Nuclear Medicine, Seoul National University Hospital, 101 Daehak-ro Jongno-gu, Seoul 110-744, Korea lipophilic agents and thus penetrate cell membranes including the blood-brain barrier (BBB) very quickly [1-4]. The penetrated agents are trapped in the brain cells by various mechanisms. The final aspects of these lipophilic agents trapped in the brain represent cerebral blood flow due to their very rapid tissue uptakes.

However, hydrophilic radiopharmaceuticals should pass through the intercellular gaps between vascular endothelial cells of the capillary to reach to the target cells, which is generally much slower than passive diffusion through the cell membrane. Specific carriers or transporters are required for transporting hydrophilic radiopharmaceuticals into the cells. For example, glucose transporters, amino acid transporters, and $\mathrm{Na}^{+} \mathrm{K}^{+}$-ATPase are required for the uptake of $\left[{ }^{18} \mathrm{~F}\right] \mathrm{FDG},\left[{ }^{11} \mathrm{C}\right]$ methionine, and ${ }^{201} \mathrm{Tl}$, respectively [5-7]. Among these, the uptake rates of $\left[{ }^{18} \mathrm{~F}\right] \mathrm{FDG}$ and $\left[{ }^{11} \mathrm{C}\right]$ methionine are much slower than ${ }^{201} \mathrm{Tl}$. Thus, the uptake patterns of $\left[{ }^{18} \mathrm{~F}\right] \mathrm{FDG}$ and $\left[{ }^{11} \mathrm{C}\right]$ methionine do not represent tissue blood flows, but glucose and amino acid uptake rates, respectively. However, uptake of ${ }^{201} \mathrm{Tl}$ through the $\mathrm{Na}^{+} \mathrm{K}^{+}$-ATPase is very rapid and represents myocardial blood flow rather than the activity of $\mathrm{Na}^{+} \mathrm{K}^{+}$ATPase.

A review article, "In vivo evaluation of ${ }^{18} \mathrm{~F}$-labeled mitochondrial voltage sensors as myocardial imaging agent using positron emission tomography," written by Kim and Min is going to be published. The fluoroalkylphosphonium derivatives including $\left(5-\left[{ }^{18} \mathrm{~F}\right]\right.$ fluoropentyl)triphenylphosphonium cation $\left({ }^{18} \mathrm{~F}-\mathrm{FPTP}\right),\left(6-\left[{ }^{18} \mathrm{~F}\right]\right.$ fluorohexyl) triphenylphosphonium cation $\left(\left[{ }^{18} \mathrm{~F}\right] \mathrm{FHTP}\right)$, and (2-(2-[ $\left[{ }^{18} \mathrm{~F}\right]$ fluoroethoxy)ethyl) triphenylphosphonium cation $\left(\left[{ }^{18} \mathrm{~F}\right] \mathrm{FETP}\right)$ are lipophilic cations that accumulate in mitochondria after passive diffusion, such as ${ }^{99 \mathrm{~m}} \mathrm{Tc}$-sestaMIBI (Fig. 1) [8]. They show very fast myocardial uptake and thus represent myocardial blood flow. 
Fig. 1 Chemical structures of lipophilic cation radiopharmaceuticals

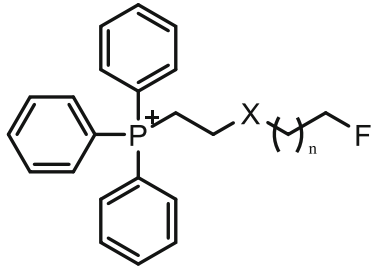

$\operatorname{FPTP}\left(\mathrm{X}=\mathrm{CH}_{2}, \mathrm{n}=1\right)$

$\operatorname{FHTP}\left(X=\mathrm{CH}_{2}, \mathrm{n}=2\right)$

$\operatorname{FETP}(X=O, n=1)$

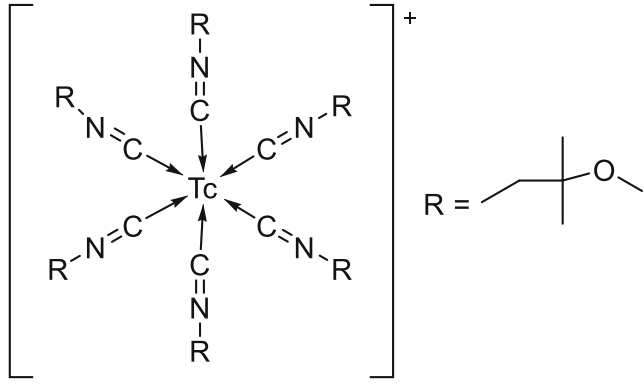

Tc-SestaMIBI
However, the efficiency of radioisotope delivery to target by small molecule radiopharaceuticals is low due to rapid renal excretion.

Various large molecules or nanoparticles have advantages of multimodality targeting or more efficient delivery of drugs or radioisotopes. However, unlike the small molecule radiopharmaceuticals, macromolecule radiopharmaceuticals, such as radiolabeled antibodies, show slow uptake to targets and sustained activity in the blood pool. They are not permeable to biological membranes and thus passes through the intercellular gaps of the capillaries to reach to the target. Also, this slow penetration from large molecular size caused slow in vivo target uptake. Blood pool activity decrease slowly because they are not excreted through the kidneys. To solve these problems, the advantage of small molecule radiopharmaceuticals was considered, which appeared as a two-step targeting strategy.

The early form of a two-step targeting strategy was the application of the avidin-biotin system, which has one of the strongest binding affinities among the existing biological systems [9]. A two-step targeting method would be performed by an administration of antibody-avidin conjugate, followed by radiolabeled biotin. After the first administration, the conjugate is distributed to target slowly. If the radiolabeled biotin is administered after a long enough distribution period, it distributes to the target fast, and the unbound fraction is excreted quickly due to its small molecular size. Although this method showed significantly improved targeting and attracted many researchers, it could not be applied widely due to several problems. The conjugate of antibody and avidin can decrease the immunoreactive fraction of the antibody due to denaturation after conjugation, which significantly decreases the uptake to the target [10]. Moreover, the conjugate has a higher molecular weight than the antibody itself, which makes it more difficult to pass through the blood capillary. Another problem with this two-step targeting method is the possibility of internalization of antibodies. It is well-known that many antibodies are internalized after binding on the surface of cells, which restricts the application of the two-step targeting system because the labeled biotin molecule is administered in the time gap of the antibody-avidin conjugate binding to cancer cell and the internalization into the cancer cell.

Recently, a bio-orthogonal two-step targeting method was developed by application of in vivo copper-free click reaction (Fig. 2) [11, 12]. This method has advantages over the previous avidin-biotin system. The chemicals used for the copperfree click reaction are small molecules, unlike avidin, and thus the molecular size of the conjugated antibody or nanoparticle does not increase significantly. Although the avidin-biotin conjugation reaction is fast, the click reaction might be faster. In addition, there is no intrinsic interfering molecule, such as biotin. However, the problem of antibody internalization still exists. A review article, "Click reaction: an applicable radiolabeling method for molecular imaging," written by Choi and Lee is going to be published.

In conclusion, the small molecule radiopharmaceuticals generally show excellent biodistribution properties; however, they show poor efficiency of radioisotope delivery. Large molecule or nanoparticle radiopharmaceuticals have advantages of multimodal and efficient delivery, but lower target-to-non-

Fig. 2 Conjugation of R and R' by using a copper-free click chemistry

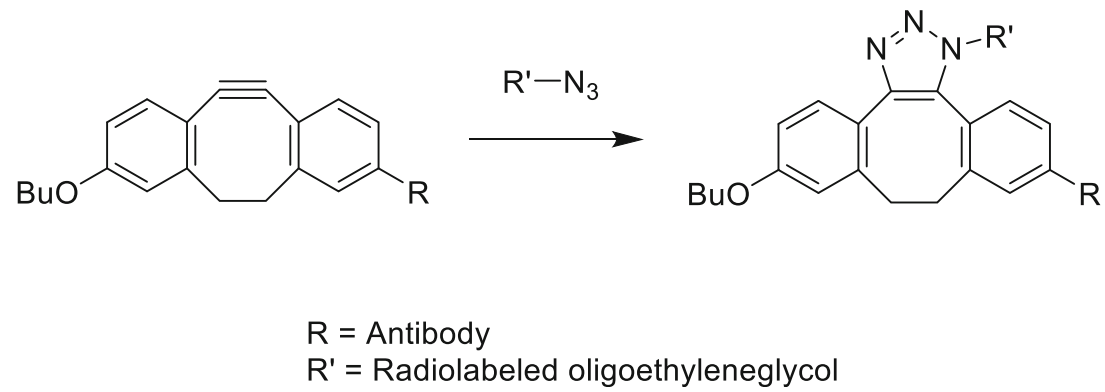


target ratio. Two-step targeting using a bio-orthogonal copperfree click reaction can be a solution of the problem of large molecule or nanoparticle radiopharmaceuticals.

Acknowledgments This study was supported by the National Research Foundation of Korea NRF-2012M2A2A7035853 and NRF2013R1A2A1A05006227.

Conflicts of Interest The author Jae Min Jeong declares that he has no conflict of interest.

Ethical Statement This article does not contain any studies with human participants or animals performed by the author. The manuscript has not been published before or is not under consideration for publication anywhere else.

\section{References}

1. Kuhl DE, Barrio JR, Huang SC, Selin C, Ackermann RF, Lear JL, et al. Quantifying local cerebral blood flow by N-isopropyl-p[123I]iodoamphetamine (IMP) tomography. J Nucl Med. 1982;23:196-203.

2. Neirinckx RD, Canning LR, Piper IM, Nowotnik DP, Pickett RD, Holmes RA, et al. Technetium-99m d, 1-HM-PAO: a new radiopharmaceutical for SPECT imaging of regional cerebral blood perfusion. J Nucl Med. 1987;28:191-202.

3. Vallabhajosula S, Zimmerman RE, Picard M, Stritzke P, Mena I, Hellman RS, et al. Technetium-99m ECD: a new brain imaging agent: in vivo kinetics and biodistribution studies in normal human subjects. J Nucl Med. 1989;30:599-604.
4. Saha GB, MacIntyre WJ, Go RT. Radiopharmaceuticals for brain imaging. Semin Nucl Med. 1994;24:324-49.

5. Phelps ME, Huang SC, Hoffman EJ, Selin C, Sokoloff L, Kuhl DE. Tomographic measurement of local cerebral glucose metabolic rate in humans with (F-18)2-fluoro-2-deoxy-D-glucose: validation of method. Ann Neurol. 1979;6:371-88.

6. Vaalburg W, Coenen HH, Crouzel C, Elsinga PH, Langstrom $\mathrm{B}$, Lemaire $\mathrm{C}$, et al. Amino acids for the measurement of protein synthesis in vivo by PET. Int J Rad Appl Instrum B. 1992;19:227-37.

7. Atkins HL, Budinger TF, Lebowitz E, Ansari AN, Greene MW, Fairchild RG, et al. Thallium-201 for medical use. Part 3: Human distribution and physical imaging properties. J Nucl Med. 1977; 18: $133-40$.

8. Kim DY, Min JJ. Synthesis and evaluation of (1)(8)F-labeled fluoroalkyl triphenylphosphonium salts as mitochondrial voltage sensors in PET myocardial imaging. Methods Mol Biol. 2015;1265:59-72.

9. Kalofonos HP, Rusckowski M, Siebecker DA, Sivolapenko GB, Snook D, Lavender JP, et al. Imaging of tumor in patients with indium-111-labeled biotin and streptavidinconjugated antibodies: preliminary communication. J Nucl Med. 1990;31:1791-6.

10. Lindmo T, Boven E, Cuttitta F, Fedorko J, Bunn Jr PA. Determination of the immunoreactive fraction of radiolabeled monoclonal antibodies by linear extrapolation to binding at infinite antigen excess. J Immunol Methods. 1984;72:77-89.

11. Baskin JM, Prescher JA, Laughlin ST, Agard NJ, Chang PV, Miller IA, et al. Copper-free click chemistry for dynamic in vivo imaging. Proc Natl Acad Sci U S A. 2007;104:16793-7.

12. Sletten EM, Bertozzi CR. Bioorthogonal chemistry: fishing for selectivity in a sea of functionality. Angew Chem Int Ed Engl. 2009;48:6974-98. 